Brankica Drašković*

Filozofski fakultet

Univerzitet u Novom Sadu
UDK 070:81'42(497.11)BLIC 070:81'42(497.5)JUTARNJI LIST

DOI: $10.19090 / g f f .2018 .2 .103-117$

Stručni naučni rad

\title{
SRPSKO-HRVATSKA KULTURNA SARADNJA U MEDIJSKOM DISKURSU ${ }^{* *}$
}

Cilj rada je bio da se metodom kritičke analize diskursa ispitaju dominantne strategije kojima se služe mejnstrim mediji u predstavljanju kulturne saradnje između Hrvatske i Srbije. Uzorak za analizu činili su tekstovi objavljeni u onlajn izdanjima dnevnih listova Jutarnji list i Blic prikupljani u periodu od 1. marta do 31. maja 2018. godine. Rezultati pokazuju da dominira spektakularizovano predstavljanje sa manipulativnim strategijama: trivijalizacije, diferencijacije, konfrontacije, prećutkivanja i zaborava kojima se izražava polarizovani odnos između suprotstavljenih grupa - srpske i hrvatske. Detektovan je i antinacionalistički diskurs kroz kritičke kontranarative u predstavljanju pojedinih tema $\mathrm{i}$ umetnika koji baštine „kulturu neslaganja i otpora“. Dualizam medijskog diskursa reflektuje, uslovno rečeno, dve forme kulturnog prostora koji paralelno egzistiraju $u$ kontekstu srpsko-hrvatske kulturne saradnje.

Ključne reči: kritička analiza diskursa, predstavljanje, kulturna saradnja, Hrvatska, Srbija, masovni mediji

\section{UVOD}

Početkom godine svi srpski mediji preneli su vest naslovljenu „Kulturna saradnja Srbije i Hrvatske odlična“. Ova štura protokolarna informacija koja je prosleđena iz kabineta ministra kulture i informisanja Republike Srbije nakon sastanka sa ambasadorom Hrvatske, uz nekoliko opštih fraza da je ,razmena između institucija kulture dve zemlje veoma intenzivna“ $i$ da se radi na „načinu produbljivanja“"1 bila je samo jedna u nizu vesti koje stižu sa adresa zvaničnika, a

\footnotetext{
* brankica.draskovic@ff.uns.ac.rs.

** Rad je nastao u okviru projekta III 47020 ,Digitalne medijske tehnologije i društvenoobrazovne promene“, koji se realizuje uz podršku Ministarstva prosvete, nauke i tehnološkog razvoja Republike Srbije.

${ }^{1}$ Primeri vesti preuzeti su sa sajtova $R T V$ i $N 1$ http://rtv.rs/sr_lat/zivot/kultura/odlicnakulturna-saradnja-srbije-i-hrvatske_888719.html,
} 
ostaju bez ikakve kritičke refleksije u medijima. Javnost je ostala uskraćena za pojašnjenje argumenata na osnovu kojih se iznosi tvrdnja o vrednosnoj oceni kulturne saradnje budući da aktuelne vlasti u obe države već decenijama unazad, neodgovarajućim kulturnim politikama i nezainteresovanošću da kroz kulturu poboljšaju međudržavnu saradnju, čine sve da minimiziraju svako nastojanje da se reše gorući problemi u ovoj oblasti. ${ }^{2}$ Bez obzira na živost saradnje umetnikâ (muzika, književnost, film), koju ostvaruju individualno ili kroz zajedničke projekte, činjenice govore da se institucionalna kulturna saradnja između Hrvatske i Srbije razvija sporo, a na njih s vremena na vreme podsećaju teoretičari i predstavnici NVO sektora koji se bave kulturom, kao i sami umetnici kad dobiju prostor u medijima.

Srbiju i Hrvatsku karakteriše nedostatak demokratske kulture i političkog pluralizma. Povratak desno orijentisanih nacionalističkih struja na političku scenu u obe zemlje u poslednjoj deceniji kritička javnost ocenjuje kao retrogradni kurs budući da po brojnim pokazateljima učvršćuju međusobno neprijateljstvo na istim manipulativnim strategijama kao i početkom devedesetih godina. Neželjene teme u javnom diskursu obaju društava i dalje su zajedničko istorijsko iskustvo (od 1918. do 1991) i suočavanje s ratnom prošlošću (od 1991. do 1996). Sve što se dogodilo u ratnim devedesetim teško se priznaje i još teže prihvata. Svaki pokušaj kritičkog sagledavanja jugoslovenske prošlosti podjednako koče veoma izraženi fenomeni ,jugofobije“63 i jugonostalgije. Prvi, revizionističkim narativima političkih elita, kontinuirano iskrivljuje činjenice o životu u prethodnoj zajednici i tekovinama antifašizma, dok se banalizacija (jugo)nostalgije i njeno guranje $u$ isključivo komercijalne okvire direktno suprotstavlja naporima da se preko kritičke kulture sećanja potisne kulturna amnezija stvorena u skoro tri decenije odvojenog života. Medijska scena u obe zemlje omeđena je brojnim lažnim vestima i politički kontrolisanim novinarstvom. Pritisci na novinare sa svih strana sve su bezočniji od

http://rs.n1info.com/a359674/Vesti/Kultura/Vukosavljevic-sa-hrvatskim-ambasadoromOdlicna-kulturna-saradnja-dve-zemlje.html

${ }^{2}$ Prema rezultatima istraživanja, koje je Desk Kreativna Evropa Srbija organizovao u cilju zajedničkog definisanja preporuka za razvoj kulturne saradnje na prostoru bivše Jugoslavije, kao najveću prepreku ispitanici su naveli nezainteresovanost vlada $(42,8 \%)$ i konfrontirajuća tumačena istorije $(20,6 \%)$,Potencijal regionalne saradnje“. Preuzeto 24. 4. 2017 sa Seecult.org (para 3) http://www.seecult.org/vest/potencijal-regionalne-saradnje

3 Viktor Ivančić (2001) „Bauk Jugoslavije“ (Preuzeto 8. oktobar 2011) Danas https://www.danas.rs/nedelja/bauk-jugoslavije/ 
ekonomskih do fizičkih pretnji. Najnovija istraživanja pokazuju da u pogledu medijskih sloboda, ni Hrvatska ni Srbija ne kotiraju visoko, a „neprijateljstvo prema medijima, koje otvoreno potiču politički lideri i napori autoritarnih režima da predstave svoju viziju novinarstva, predstavljaju ozbiljnu pretnju za demokratiju“‘ ${ }^{4}$ U onlajn komunikaciji građana na internet portalima i društvenim mrežama se „mahanje nacionalnim zastavama snažno podupire vatrenom retorikom sa obe strane“" (Drašković, 2014: 344). Nisu retki ni slučajevi medijskih tekstova koji eksplicitno ili implicitno potpiruju mržnju bilo da se radi o komemoracijama događaja iz prošlosti ${ }^{5}$, sportskim manifestacijama $^{6}$ ili muzici. $^{7}$

Imajući u vidu celokupan društveno-politički, kulturni i medijski kontekst, cilj rada bio je da se ispitaju diskursne strategije kojima se služe neki od najuticajnijih mejnstrim medija u Hrvatskoj i Srbiji u predstavljanju kulturne saradnje - događaja i aktivnosti umetnika iz ove dve zemlje. Polazna pretpostavka je da spektakularizovano izveštavanje s jedne strane, a politika stereotipizacije i korišćenje manipulativnih strategija revanšizma, osporavanja, prećutkivanja $i$ zaborava $\mathrm{u}$ predstavljanju prošlosti, $\mathrm{s}$ druge strane, sinergijski osnažuju nacionalistički diskurs iz vremena dezintegracije $\mathrm{SFRJ}^{8}$ i ratnih dejstava tokom devedesetih godina (Drašković, 2016).

${ }^{4}$ Prema izveštaju Reportera bez granica Srbija je pala za 10 mesta u odnosu na prošlu godinu (sa 66. na 76. mesto), dok je Hrvatska na 69. mestu na listi medijskih sloboda. https://rsf.org/en/rsf-index-2018-hatred-journalism-threatens-democracies

5 Hrvatska i Srbija u pogledu razumevanja ratnih operacija i njihovih posledica i dalje održavaju takozvani 'ćuteći konflikt'. U srpskoj javnosti stvoren je mit o stradanju i porazu, u hrvatskoj o velikoj pobedi nad neprijateljem, o junaštvu i ponosu i taj narativ se stalno utvrđuje. Najbolji primer je slučaj obeležavanja godišnjice vojne operacije Oluja, koja se u Hrvatskoj slavi kao Dan pobjede i Dan domovinske zahvalnosti, a u Srbiji kao Dan žalosti.

6 Svetsko prvenstvo u fudbalu (Rusija 2018) bilo je poligon za rasplamsavanje nacionalističkog diskursa u oba društva. Detaljnije u tekstu Fudbal u glibu nacionalizma $i$ šovinističke mržnje. Preuzeto 11. 7. 2018 sa http://balkans.aljazeera.net/vijesti/fudbal-uglibu-nacionalizma-i-sovinisticke-mrznje

7 Otkazivanje nastupa beogradskih muzičara Bajage i Instruktora u Hrvatskoj koji su inicirala braniteljska udruženja šireći neistinite informacije, u javnosti obe zemlje ponovo je pokrenuto pitanje podgrevanja nacionalističkog diskursa. Detaljnije u tekstu Pjevači $i$ huškači. Preuzeto 17. 8. 2018 sa https://www.portalnovosti.com/pjevaci-i-hukaci

${ }^{8} \mathrm{U}$ brojnim studijama potvrđena je teza da su se neki od ključnih događaja pre i za vreme rata desili upravo kao reakcija na medijsku prezentaciju događaja (Tompson, 2000; Čolović, 1993; Ramet, 1996; Slapšak, 1997; Skopljanac, Bruner, 1999; Milivojević, 1996; Bugarski, 1997; Reljić, 1998; Kolsto, 2008; Kurspahić, 2003) (Drašković, 2016). 


\section{ZAJEDNIŠTVO UZAJAMNOG RAZUMEVANJA}

Prihvatljiva definicija kulturne saradnje za rad deo je koncepta panevropskog javnog prostora kao jednog od ključnih subjekata međunarodne saradnje koji se primenjuje na nivou Evropske unije ${ }^{9}$. Oslanja se na Habermasov koncept javnosti odnosno „komunikativnog delanja“ koje „navodi aktere da se međusobno prihvate kao govornici i slušaoci, insistirajući na uzajamnim zahtevima koji se mogu prihvatiti ili osporiti“, a ono može da se sprovodi „kroz zajedništvo uzajamnog razumevanja koje je zasnovano na prepoznavanju kompatibilnosti individualnih vrednosti“ (Habermas, 1984, prema Wiesand, 2005: 19). Kulturnu saradnju tako možemo posmatrati kao komunikacijski proces ,u kojem individualni i institucionalni učesnici preduzimaju aktivnosti i mere s ciljem mobilizacije $i$ razmene umetničkih ili kulturnih dobara između pojedinaca, grupa i institucija u Evropi““ (Wiesand, 2005: 20). Javlja se u bilateralnom i multilateralnom obliku, a poseban vid kulturne saradnje predstavljaju međunarodne kulturne manifestacije, kao i učešće pojedinačnih stvaralaca na festivalima ili projektima u inostranstvu kojim doprinose afirmaciji matične kulture (Dragićević Šešić - Stojković, 2007: 324).

Kulturna saradnja između Hrvatske i Srbije ne može se odvojeno posmatrati od konteksta širih političkih i ekonomskih odnosa koji su u evrointegracijskom procesu stavljeni pod političku odrednicu region Zapadnog Balkana. ${ }^{10}$ Reč je o kulturama naroda koje su rasle približno istim korakom u zajedničkoj državi, kroz dva politička projekta (Kraljevina SHS i Jugoslavija) u periodu dužem od sedam decenija, u okviru jednog standardnog jezika i u međusobnoj kulturnoj korelaciji tokom 20. veka, ali koje već više od četvrt veka unazad na svom samostalnom putu obojene nacionalističkom ideologijom političkih i intelektualnih elita predstavljaju poligon za izražavanje međusobne netrpeljivosti. Današnji institucionalni okvir razvoja međusobne kulturne saradnje dveju država

\footnotetext{
${ }^{9}$ Projekat koji podržava ovaj koncept je Kompendijum kulturne politike u koji su uključene i Srbija i Hrvatska. Reč je o internet sajtu organizacije ERICarts (The European Institute for Comparative Cultural Research) i Saveta Evrope, koji omogućuje informisanje najšire javnosti o instrumentima i prioritetima nacionalnih kulturnih politika.

${ }^{10}$ Region se odnosi na celinu više država ,,koje povezuje teritorijalna i kulturna bliskost, ali i ekonomski i politički faktori“ (Mihajlov, 2010: 310). Prvobitno je prostor koji su činile nekadašnje republike bivše Jugoslavije u novom istorijskom kontekstu označavan kao region Jugoistočne Evrope. Od 2007. godine preimenovan je u region Zapadnog Balkana, a obuhvata Albaniju, Bosnu i Hercegovinu, Srbiju, Makedoniju, Hrvatsku i Crnu Goru.
} 
omogućio je proces evrointegracija ističući ,višedecenijsko kulturno zajedništvo ili kulturno raspoznavanje, ekonomske razloge (povećanjem tržišta povećava se i broj potrošača) i zajednički pristup, koji poboljšava položaj kreativnog rada u uslovima evropskih globalnih procesa“ (Vujadinović, 2009: 100 prema Mihajlov, 2010: 311). Međutim, jezik, istorijske veze, kao i teritorijalna blizina ,ma koliko delovali kao preduslov za ostvarivanje kulturne saradnje, tokom istorije su baš ti faktori često bili i uzrok sukoba i dezintegracije“" (Ibid.). Primer su devedesete godine kada pod uticajem tih faktora dolazi do prekida komunikacije na svim nivoima, negacije zajedništva, okretanje ka kulturnom tradicionalizmu, krize identiteta i procesa ,anakulturacije“. ${ }^{11} \mathrm{Na}$ putu uspostavljanja novog kulturnog sistema Hrvatska prolazi transformaciju čuvajući institucionalni okvir, ali radikalno menjajući vrednosno-ideološki koncept, dok Srbija učvršćuje institucionalni sistem unutar autoritarnog režima, koji karakteriše sveukupna moralna i vrednosna kriza (Dragićević Šešić - Stojković, 2007). U Srbiji je usvojena mešavina jugoslovenstva i srpskog nacionalizma, a Hrvatska je insistirala na potpunom raskidu s jugoslovenskom prošlošću (Jansen, 1998. prema Jansen, 2005: 181) pri čemu je „dominantni narativni diskurs sve tri sjedinjene 'drugosti' (komunističku/ jugoslovensku/srpsku) smatrao istovetnim i jednako opasnim, te je zahtevano njihovo isključenje iz javnog prostora i nove nacionalne svesti“" (Bejker, 2011: 18). Iz sredstva komunikacije, jezik je ,pretvoren u sredstvo podjele, postajući tako međaš razgraničenja i izgradnje novih nacionalnih i kulturnih identiteta“" (Drašković, 2014: 171), a na isticanju njegovih razlika više su radili političari nego lingvisti. ${ }^{12}$ Tako je diskurzivna mogućnost pripadanja i 'hrvatskoj' i 'srpskoj' kulturi zapala u krizu. Relativna nedvosmislenost lingvističke granice pretvorila se u ,čvrst kriterijum diferencijacije“ (Bejker, 2011: 127) i iskristalisala dva osnovna pitanja ,(1) kako biti različit, i (2) koliko različito je dovoljno različito“ (Bugarski, 2005: 166). Zajedničko kulturno nasleđe postalo je „mrtvo“ na svim stranama. Jugoslovenski pisci, filmski, pozorišni i muzički i drugi umetnici i njihova dela

\footnotetext{
${ }^{11}$ Označava trend „nastojanja da se kulturne razlike interpretiraju u etničkom ključu i odatle izvede zaključak o nemogućnosti multikulturnog društva... kako bi mogla da se označi jedna od matrica kulture i socijalne dezintegracije tokom koje su još od nestvorenih Jugoslovena postali ekskluzivni Srbi, Hrvati, Bošnjaci““ (Stojković, 2002: 20).

12 Pojedini naučnici brane tezu da novonastala četiri jezika hrvatski, srpski, bosanski i crnogorski predstavljaju jedan - ,policentrični srpskohrvatski jezik“ koji se definiše kao ,jezik s nekoliko nacionalnih standardnih varijanti“" (Kordić, 2010: 57).
} 
postaju predmet nacionalnog identitetskog razvrstavanja i međunacionalnih razmirica.

Celokupna društveno-politička i kulturna klima se menja sa simboličnim ulaskom u novi milenijum koji je obeležila Tuđmanova smrti u Hrvatskoj i pad Miloševića u Srbiji. U Hrvatskoj se javljaju težnje za oblikovanjem nove kulturne politike ka „pluralističkom kulturnom usmerenju“ što je podrazumevalo „uravnoteženiji pristup tradicije i novo vrednovanje nacionalnih i multikulturnih komponenti, a preduzeti su i koraci ka daljnjoj decentralizaciji i izravnoj suradnju s nevladinim organizacijama" (Švob Đokić-Primorac-Obuljen, 2013: 1). Urušeno stanje u kulturi bilo je veliki izazov i novoj demokratskoj vlasti u Srbiji „u odnosu na sopstveni društveno-politički i kulturološki okvir, kao i pred konceptima vezanim za identitet, a koji bi ispunili taj okvir" (Rogač, 2010: 333). Predpristupni fondovi Evropske unije počinju intenzivnije da podupiru projektne aktivnosti usmerene ka ponovnom povezivanju, a potpisuju se i konkretni sporazumi ministarstava kulture Srbije i Hrvatske o institucionalnom povezivanju. Iako je godinama kamen spoticanja bio zbog političkog pragmatizma poželjan stav „tamo nikad više!“, postojali su i primeri umetničkih projekata čiju saradnju su direktno podržavali predsednici, premijeri i ministri kulture. ${ }^{13}$ Međutim u obe zemlje sa povratkom desno orijentisanih struja stanje se pogoršava i vraća na početak devedesetih. Angažovani umetnici iz gotovo svih umetničkih disciplina sve vreme ostaju na margini interesa, a po potrebi se u kontekstu moralizatorskog diskursa stigmatizuju kao državni neprijatelji i ,izdajnici“ u matičnim zemljama. Paradoksalno, estradna scena bila je i ostala najjači potporni stub srpsko-hrvatske kulturne saradnje na dominantnoj populističkoj matrici čije uporište su bili i ostali mas-mediji tabloidne provenijencije.

Kamen spoticanja u normalizaciji institucionalnih odnosa dveju zemalja već dugi niz godina je vraćanje iz Srbije kulturnih dobara otuđenih tokom rata $u$ Hrvatskoj. ${ }^{14} \mathrm{O}$ tom procesu već godinu dana nema nikakvih informacija u javnosti.

${ }^{13}$ Zagrebačka, Beogradska i Ljubljanska filharmonija su, od sezone 2011/12, inicirale novi vid regionalne saradnje pod simboličnim nazivom Pika-Točka-Tačka.

${ }^{14}$ Potražuju se na desetine hiljada muzejskih predmeta i kulturnih dobara, koje hrvatska strana vidi kao opljačkane a srpska kao sklonjene i spašene od ratnih dejstava. U periodu od 2001. do 2013. u Hrvatsku vraćeno 25.260 umetničkih dela, a 2012. godine potpisan je i sporazum između dvaju Ministarstava kulture. Nakon što su predstavnici Hrvatske 2014. godine zatražili od Evropskog parlamenta u Strazburu da povratak „hrvatskog kulturnog blaga tokom rata devedesetih bude deo pregovaračkog paketa za ulazak Srbije u EU“" proces 
Medijski diskurs nekritički preslikava dominantni politički diskurs u čijem zvaničnom interesu politike pamćenja na rat nisu sećanja na sopstvena nedela. Odbacivanje krivice $\mathrm{u}$ javnosti se razvija kroz strategiju 'preskriptivnog zaboravljanja' (prescriptive forgetting) (Connerton, 2008: 71), koja „može imati za cilj zaštitu opšteg državnog i društvenog interesa“, ali i 'strukturalne amnezije' (structural amnesia), koja se obično primenjuje da bi se izbrisali društveni i kulturni 'nevažni' trenuci za željeni 'konstruisani narativ identiteta'“ (Ibid). O temi otuđenog kulturnog dobra iz Hrvatske se nakon rata malo ili nikako govorilo u srpskoj javnosti, zbog prethodnog prećutkivanja o učinjenom, tako da sadašnja strategija predstavljanja ove teme u medijima može da se tumači prema ustanovljenoj kategoriji zaboravljanja i kao 'sramotne tišine' (shameful silence) koja kao „kontroverzna, povezana s različitim emocijama (sram, krivnja, i sl) (Dragičević Šešić-Stefanović, 2014) izostavlja činjenice iz službenog sećanja (Drašković, 2016: 160-161).

\section{KONCEPT MEDIJSKOG PREDSTAVLJANJA I METODE}

Kako bismo utvrdili medijski diskurs kulturne saradnje, oslanjamo se na koncept medijskog predstavljanja kao ideološkoj 'politici označavanja' (Hall, 1982: 64) čiji cilj nije samo prenošenje postojećeg nego i učitavanje drugačijeg značenja, dok oslonac u metodološkom delu pruža kritička analiza diskursa (KAD). Korišćen je sociokognitivni pristup Van Dejka, koji nudi dubinsku analizu mikrostruktura jer „omogućuje da se utvrde društvene tvrdnje i pretpostavke, kao i druge implikacije novinskog diskursa koje mogu biti relevantne za ideologije koje su u njihovoj osnovi“ (Van Dijk, 1988: 170). Za istraživanje diskursa kolektivnih entiteta 'mioni', mediji čine plodno tle jer značenje ovih zamenica je delimično određeno kontekstom u kojem se koriste i ističu identifikaciju sa pripadnicima jedne, a udaljavanje od članova druge grupe. „Ova simbolička moć medija omogućava nam da objasnimo njihovu ulogu u reprodukciji etnonacionalne ideologije, jer političke i ideološke poruke koje u sebi nose medijske predstave omogućuju retorički prostor za nacionalistički diskurs“ (Van Dijk, 1989, prema Džihana - Volčić, 2011: 15). Tragovi „banalnog nacionalizma“ često su zastupljeni kroz kratke i neupadljive reči

je intenziviran. Do kraja 2017. godine vraćeno je 29.779 predmeta, a međudržavno „Povjerenstvo za povrat kulturnih dobara“ nastavlja sa radom na povratu preostalih, stoji u izveštaju Ministarstva kulture Republike Hrvatske. 
poput patriotskog 'mi' , koje se nikada ne odvaja od 'oni' „one nas smeštaju u domovinu, u okviru sveta nacije“" (Bilig, 209: 310).

Korpus za analizu činila su onlajn izdanja lista Blica (www.blic.rs) i Jutarnjeg lista (www.jutarnji.hr) u tromesečnom vremenskom periodu od 1. marta do 31. maja 2018. godine. Njihov izbor uslovilo je nekoliko faktora: važe za najposećenija onlajn izdanja štampanih medija, oba imaju polutabloidni profil, ali su zadržali rubrike kulture za koje pišu specijalizovani novinari. Posmatrani su i uzorkovani oni tekstovi koji su se odnosili na aktivnosti (individualne i institucionalne) umetnika (u vidu događaja ili teme) u međusobnoj kulturnoj saradnji Srbije i Hrvatske, zatim na zajedničke kulturne projekte, festivale, ali i personalizovane vesti o umetnicima. Jedinica analize u onlajn uzorku Blica (blic.rs) i Jutarnjeg lista (jutarnji.hr) pojedinačni tekst, šifriran je i nosi skraćenu oznaku medija $(B L, J L)$, kao i datum objavljivanja. Izdvojeno je 50 tekstova (15 Jutarnji list) i (35 Blic) na kojima je sprovedena dubinska analiza sintaksičke i semantičke strukture, izbor leksike (prideva, glagola, fraza itd.) metafora, korišćen za opisivanje događaja i aktera u naslovnom bloku i tekstu. Korišćeni su i različiti oblici kabinetskog istraživanja (analiza podataka dostupnih u tekstovima/istraživanjima drugih autora, itd.).

\section{REZULTATI ISTRAŽIVANJA I DISKUSIJA}

Analiza pokazuje da se u pogledu predstavljanja kulturne saradnje i srpski i hrvatski mediji oslanjaju uglavnom na spektakularizovano izveštavanje na individualnom nivou. Institucionalna saradnja, nezavisna kulturna scena, kao i teme iz domena kulturne politike potpuno su skrajnute ili nevidljive. Višegodišnje sistematsko podgrevanje mržnje i gušenje ,zajedništva uzajamnog razumevanja“ u kontekstu novoizgrađenih nacionalnih kulturnih identiteta, generalno je smanjilo interes (Drašković, 2016). Potvrđuju to i disonantni glasovi o postojanju postjugoslovenskog kulturnog prostora ,Rundek vjeruje da je kultura i dalje zajednička... Ivaniš u potpunosti negira... Čitava ta kultura temeljena na zajedničkom jeziku metaforički stane u čašu jogurta. Pritom vrijeme odigra svoje pogotovo kad se jogurt otklopi i ne čuva na hladnom i tamnome mjestu“ ističe se u tekstu 1) „Priča o stvaranju i nestajanju zajedničkog kulturnog prostora“ (JL, 30. 3. 2018). Analizom je uočen dualizam nacionalističkog i antinacionalističkog medijskog diskursa koji se ogleda s jedne strane kroz diskurs trivijalizacije, diferencijacije, konfrontacije, prećutkivanja $i$ zaborava, a sa druge kroz diskurs kritičkih kontranarativa. Trivijalizaciju izveštavanja o kulturnoj saradnji poput vesti 2) „SKRASIO SE NAJPOŽELJNIJI HRVATSKI NEŽENJA Nakon raskida sa 
Rozgom, oženio se Stjepan Hauser“ (BL, 1. 4. 2018) opravdava tržišno orijentisani medijski koncept koji ,gaji duboki prezir prema publici kojoj se obraćaju, smatrajući da se ona navodno zadovoljava medijskim sadržajima koje najviše voli: zabavom, lakim žanrovima, senzacionalnošću i nasiljem“ (Đorđević, 2011: 11). Za takvu publiku plasiranje ozbiljnijih tema iz domena kulture zapravo je ,uludo protraćen medijski prostor“ (Ibid.). U tekstovima koji nisu iz korpusa šou biza uočljiv je diskurs diferencijacije $i$ konfrontacije koji odlikuje ideološka podela na dobri 'mi' i loši 'oni'. Za razliku od prethodnog istraživanja kada je nacionalistički diskurs bio 'umiveniji' i 'skriveniji' (Drašković, 2016), sada je postao izraženiji. Dobar primer je nekoliko vesti u nizu nastalih kao reakcija na objavu hrvatskog koreografa i nekadašnjeg baletskog prvaka Državne opere u Berlinu Ronalda Savkovića na Fejsbuku koje su u senzacionalističkom maniru pretvorene u predmet obračuna i javne polemike o opravdanosti srpsko-hrvatske kulturne saradnje 3),,JEDVA OSTADOH ŽIV U SMRDIJI Hrvat radio na predstavi u Beogradu i napljuvao nas toliko da ćete se ŠOKIRATI“ (BL, 29. 5. 2018); 4) „Upravnik Narodnog pozorišta o hrvatskom koreografu: On je ozbiljan umetnik, ali je i MAGARAC“ (BL, 31. 5. 2018); 5) „Hrvatski koreograf koji je Srbiju nazvao „Smrdija“ dobio odgovor na koji TREBA DA BUDEMO PONOSNI“ (BL, 31. 5. 2018).

Upotrebom indikatorskih reči može da se odredi ,polazna tačku s koje se piše određeni tekst“ i sugeriše čitaocima kako da se postave ,unutar ili izvan grupe predstavljene u tekstu“ (Mihelj, Bajt, Pankov 2008: 102), a novinar u navedenom primeru iznošenjem eksplicitno pristrasnog stava već u naslovima tekstova postavlja jasnu identitetsku liniju razdvajanja između grupa koje predstavljaju konfrontirani hrvatski i srpski umetnici u Fejsbuk prepisci. Uključujući u naslovu etničku identifikaciju Hrvat, umesto umetničke - koreograf, zatim žargonsku sintagmu „napljuvao nas“ (3) kao i pristrasan komentar da je umetnik dobio odgovor na koji ,treba da budemo ponosni““(5) jasno se konfrontira i kroz banalno patriotsko 'mi' (Bilig, 2009) i postavlja naspram predstavnika druge etničke grupe. Negativna predstava o 'njima' uvek mora biti praćena pozitivnom slikom o 'nama' i obrnuto te se književnik Aleksandar Gatalica (5) kao institucionalni glas ${ }^{15}$ javno obračunava sa hrvatskim umetnikom navodeći gde se Srbija uspešnije kotira na kulturnoj mapi sveta od Hrvatske. „Kulturnu scenu Srbije smatram najdominantnijom $u$ regionu Balkana, ne samo u jednoj odnosno drugoj umetnosti... već u celosti... poredak zemalja po broju ulazaka na najveći govorni

${ }^{15}$ Trenutno na funkciji predsednika UO Narodnog pozorišta 
sajt poezije na internetu Lyrikline u Berlinu: ... Srbija na četvrtom mestu 35.266, moram dodati i ovo Hrvatska na 40. mestu sa 1.825 ulazaka. “

Tendenciozan urednički potez da ispod ovog teksta postavi video prenet sa sajta index.hr 6) „Pitali su hrvatske maturante šta misle o Srbiji, odgovori su ih šokirali“, u kojem se navodi da „Evropska komisija protiv rasizma i netolerancije upozorava kako među mladim Hrvatima jača nacionalizam i to često $u$ obliku veličanja ustaškog režima“ primer je manipulacije i direktnog podgrevanja neprijateljske predstave o drugom. Primer, „simboličkog fiksiranja razlike između 'nas' i 'njih'“ (Hall, 1997) javlja se i kroz strategije prećutkivanja i zaborava kao direktne posledice procesa „konfiskacije jugoslovenskog kolektivnog pamćenja i njegove zamjene konstruktom nacionalnog pamćenja (Ugrešić, 2008: 315) koji od početka devedesetih godina u javnom diskursu nijednog od dva društva nikada nije napušten. Identitetsko razgraničavanje ko kome pripada iz zajedničkog jugoslovenskog nasleđa ${ }^{16}$ uočeno je u nekoliko primera. U najavi događaja 7) „Dani srpskoga filma u Tuškancu“ (JL, 11. 4. 2018), dela nastala u okviru jugoslovenske kinematografije kao što su „Skupljače perja” (1967); „Ko to tamo peva“ (1980), itd, svrstavaju se u nacionalni korpus ,antologijskih ostvarenja srpske kinematografije“, a indikativan je i primer teksta pod naslovom 8) „JOVAN ILI JOHN? Srpski povjesničari su ga odavno prisvojili, ali u novinama iz 1932. jasno piše: 'Ne sramuje se hrvatskega imena, pač pa je ponosen na svoj rod'“ (JL,12. 3. 2018). Bez konkretnog povoda poseže se za 'odbranom' nacionalnog identiteta davno preminulog američkog glumca Džona Mildžana (1892-1960), koji je, po mišljenu autora teksta, „nepravedno zaboravljen u hrvatskoj filmskoj literaturi“, dok su ga „Srbi već odavno proglasili svojim sunarodnjakom davši mu, štoviše, novo kršteno ime $i$ prezime“. U međunaslovu teksta „Čiji je Miljan“ autor sugeriše kako je za „pokrštavanje“ glumca direktno odgovoran beogradski dnevni list Vreme jer je 1934. godine objavio pismo Miljanovog daljeg rođaka o njegovom poreklu što je „označilo početak stvaranja mita o “Jovanu Miljanoviću”. Deo pisma u kojem stoji da je Miljanov otac „kao vatreni Srbin, nosio narodnu srpsku kapu iz mržnje prema Austriji“, te da je „nemoguć da i dalje podnosi neprijateljski zulum pošao je u Ameriku, autor demantuje: „Ekonomski razlozi iseljenja zamijenjeni su, dakle, političkim, a bunt protiv Monarhije pomiješan je s osjećajem nacionalne pripadnosti“. Iako se na kraju teksta pita „Što bi o svemu tome mislio John Miljan,

\footnotetext{
${ }^{16}$ Svojatanje znamenitih ličnosti iz jugoslovenskog nasleđa čest je predmet srpsko-hrvatskih razmirica. Najveće polemike vođene su oko toga kome pripadaju svetski priznati naučnik Nikola Tesla i književnik Ivo Andrić
} 
dakako, ne znamo“ autor, ipak, čitaocu sugeriše da on ,pripada krugu uspješnih Amerikanaca hrvatskih korijena".

$\mathrm{U}$ analiziranom korpusu uočen je i antinacionalistički diskurs, a predstavljaju ga glasovi tzv. ,kritičkog kontranarativa“ (Drašković, 2016). U tim tekstovima je opozicioni odnos ideološkog predstavljanja 'mi' i 'oni' postavljen u drugačiju konstelaciju snaga. Ovde je 'mi' sa individualne pozicije koju čine 'ja' (antinacionalist) postavljeno naspram kolektivističkog 'oni' (nacionalisti obeju strana). U svim negativnim primerima relacije 'mi-oni' ilustruju antagonizam odnosno dominaciju jedne etničke grupe prema drugoj, dok je u ovom drugom primeru diskursa izražen prema predstavnicima nacionalističkog diskursa. U intervjuu za Blic 9) „Neću se miriti sa stanjem stvari“ (BL, 23. 5. 2018) pozorišni reditelj Oliver Frljić, čije predstave kao primer političkog teatra upravo konstruišu „kontrajavnost“", odgovorom na pitanje novinarke „,na koji način je kultura čelična metla nacije“ sublimira taj odnos: „Mogla bi počistiti sve nas koji smo nečisti u ideji nacionalno čiste kulture. Ono što se radi u Srbiji $i$ u Hrvatskoj to vrlo očigledno pokazuje.“ U kritičkom tonu i frontmen zagrebačke rok grupe „Hladno pivo“ Mile Kekin 10) „, Na delu je ukidanje istine i morala" (BL, 26. 5. 2018). u odgovoru na pitanje novinara ,Zašto je nekim ljudima potrebno konstantno podgrevanje nacionalnih strasti“" konstruiše kontranarativ: „Moraš naći krivca za činjenicu da unazađuješ zemlju koju si nasledio. Za to je potreban huškački stroj koji će podgrejati strasti kako ljudi ne bi mislili nego osećali“. U analitičkom tekstu 11) „Kako su srpski filmovi postali po ukusu hrvatskih nacionalista“ (JL 8. 4. 2018) o sličnostima i razlikama srpske i hrvatske kinematografije autor se argumentovano kritički osvrće na domete stvaralaštva, ali i na paralelizam stanja u oba društva: „Najljepše bi bilo kad bi se moglo spojiti bolje strane obje kinematografije. Ali, ne živimo u savršenom svijetu - ne živi nitko, a bome - Srbi i Hrvati ponajmanje “. Kao alternativa govoru mržnje i ksenofobičnim predstavama u nekim tekstovima može poslužiti i intervju sa rediteljem iz Srbije Ognjenom Glavonjićem u kojem se odbacuju i konstrukt nacionalnog i revizionističkog narativa u javnom diskursu 12) „Film se treba obraćati mladim fašistima. On ih treba obrazovati, razbijati zablude i mitomanije“ (JL, 12. 5. 2018). Novinar ističe da je zanimljivost filma „Teret“ u tome što referiše na partizansku baštinu ,, Teret kao da propituje apsurd: jedna generacija sama je bila žrtva i bacana u masovne jame, generacija njihovih sinova sada u masovne jame baca druge... Upravo zato Glavonić napominje da se osjeća kao Jugoslaven i citira Viktora Ivančića: „Budući da živimo u ambijentu gdje je Jugoslavija oglašena kao najgora psovka, upravo jugoslavenska etiketa nudi aktivniju poziciju i obilježava odgovorniji model antinacionalizma. “ 


\section{ZAKLJUČAK}

Politika označavanja srpskih i hrvatskih medija u kontekstu predstavljanja kulturne saradnje je višedimenzionalna što je odraz kompleksnosti društvenopolitičkog i kulturnog konteksta. Dualizam u medijskom diskursu nacionalističkog i antinacionalističkog ukazuje na postojanje, uslovno rečeno, i dveju formi kulturnog prostora koji paralelno egzistiraju u kontekstu kulturne saradnje između Hrvatske i Srbije: spektakularizovani (većinski) i kritički (manjinski). Oba imaju svoje narative koji se reflektuju u medijima. Prvi karakteriše strah od drugog i isticanje različitosti, govor mržnje, podrška revizionističkim idejama političara, prećutkivanje i zaborav prošlosti, a drugi prihvatanje drugog, isticanje sličnosti i jezičkog razumevanja, kritičko suočavanje sa prošlošću, otpor mitologizaciji i nacionalnim konstruktima kao i reviziji antifašističke prošlosti. Većinski je dominantniji, njegovo uporište u medijima je strategija trivijalizacije, konfrontacije, prećutkivanja, zaborava dok manjinski baštini 'kulturu neslaganja i otpora' kroz kritičke kontranarative. Mediji zapravo nemaju jasnu strategiju u predstavljanju aktera kulturne saradnje ona se odvija stihijski i prepuštena je diskursima koje privatno zastupaju novinari. Prisustvo nacionalističkog diskursa je opasno i vodi $u$ dalju legitimizaciju političkog diskursa i trivijalizaciju života. Antinacionalistički diskurs kao otpor (Jansen, 2005) dominantnom javnom govoru i simboličkom odmeravanju 'nas' i 'njih' ne bi trebalo da bude prepušten pojedincima već mora biti deo jasne uređivačke politike i svesti o odgovornosti medija. Potvrđujući Van Dejkov argument o odnosima između medijskog diskursa i ideologije, mogu se posmatrati kao potencijalna prepreka u procesu razvoja kulturne saradnje. Podilaženje neukusu i odsustvo kritičkog dijaloga u većini medijskih sadržaja teško može da inicira šire rasprave i doprinese bržim promenama i unapređenju stanja ne samo u kulturi, nego i celokupnom društvu, kao i u prevazilaženju neprijateljske prošlosti kada su u pitanju Hrvatska i Srbija. 
Brankica Drašković

SERBIAN-CROATIAN CULTURAL COOPERATION IN MEDIA DISCOURSE

\section{Summary}

The subject of this paper is the discourse representation of cultural cooperation between Croatia and Serbia in media texts. The aim was to examine the dominant strategies used by the mainstream media in Croatia and Serbia in the representation of appearances, events and the activities of artists from the two countries by using the method of critical discourse analysis. The sample for analysis consisted of texts published in online editions of the daily newspapers Jutarnji list and Blic collected during March, April and May of 2018. The results of the research show that the dominant strategy is spectacular representation, primarily on an individual level. Unlike in previous research, when nationalistic discourse was influenced by an already existing socio-cognitive basis originating on the ideological division 'We' and 'They' and was 'more clandestine and hidden' than the one in the nineties, it has now become articulated. It is shaped by almost all manipulative strategies differentiation, confrontation, silence and forgetting, which express the polarized relationship between the opposing groups, Serbian and Croatian. Through the patriotic discourse of well-known stereotypes that support the uncoordinated social and political narratives of Serbia and Croatia, first and foremost those of the past, journalists are pointing out explicit negative valuations towards the actors uniting themselves with members of their own group, defending and clearly distancing themselves from members of the other group, which is attacked. On the other hand, the detected antinationalist discourse in the form of critical counter-narratives of the representation of certain subjects and artists follows the tradition of a "culture of disagreement and resistance" to the current circumstances. The detected dualism of nationalist and anti-nationalist discourse in our research indicates the existence of, in a manner of speaking, two parallel forms of cultural space in the context of cultural cooperation between Croatia and Serbia.

Keywords: critical discourse analysis, presentation, cultural cooperation, Croatia, Serbia, mass media

\section{LITERATURA}

Bejker, K. (2011). Zvuci granice. Beograd: Biblioteka XX vek.

Bilig, M. (2009). Banalani nacionalizam. Beograd: Biblioteka XX vek.

Bugarski, R. (1997). Jezik u društvenoj krizi.Beograd: Čigoja.

Connerton, P. (2008). Seven types of forgetting. Memory studies. Vol 1(1): 59-71.

http://www.history.ucsb.edu/faculty/marcuse/classes/201/articles/08Connerton7Typ esForgetting.pdf

Dragićević Šešić, M., Stojković, B. (2007). Kultura: menadžment, animacija, marketing. Beograd: Clio. 
Dragićević Šešić, M., Stefanović, M. (2014). Organizational trauma and policies of oblivion - types of organizational forgetting in the case of Belgrade theatres. Rad izložen na konferenciji: 22nd ENCATC Annual Conference, New Challenges for the Arts and Culture, Brno, 17-19 September 2014.

Drašković, B. (2016) „Izveštavanje ili spektakularizacija: predstavljanje kulturne saradnje u srpskim i hrvatskim medijima“ (Nepublikovana doktorska disertacija). Fakultet dramskih umetnosti, Univerzitet umetnosti u Beogradu, Beograd.

Drašković, B. (2014). Nacionalistički diskurs i predstave o drugom u komentarima čitalaca onlajn izdanja Blica i Jutarnjeg lista. U: Valić Nedeljković, N., Sremac, S.

Knežević, N., Gruhonjić, D. (ur.) Uloga medija u normalizaciji odnosa na Zapadnom Balkanu (str. 341-361). Novi Sad: Filozofski fakultet u Novom Sadu.

Drasković, R. (2010). Re-Imagining Yugoslavia: Learning and Living with Diverse Cultural Identities. University of Toronto. Preuzeto 12. 5. 2016 sa https://tspace.library.utoronto.ca/bitstream/1807/25644/1/Draskovic_Radoslav_20 1011_MA_thesis.pdf.

Đorđević, J. (2009). Postkultura. Beograd: Clio.

Džihana, A. Volčič, Z. (2011). Uvod: Ka mirovnom novinarstvu. Mediji $i$ nacionalne ideologije: Analiza izveštavanja o suđenjima za ratne zločine $u$ bivšoj Jugoslaviji (str. 7-37). Sarajevo: Mediacentar.

Hall, S. (1982). The rediscovery of ideology: the return of the repressed in media studies. In Gurevitch, M. et al. (eds.). (pp. 56-90). Culture, society and the media. London: Methuen

Jansen, S. (2005). Antinacionalizam. Beograd: Čigoja štampa, Biblioteka XX vek.

Kordić, S. (2010). Jezik i nacionalizam. Zagreb: Durieux.

Mihajlov, J. (2010). Regionalna kulturna saradnja u jugoistočnoj Evropi. Kultura: časopis za teoriju i sociologiju kulture i kulturnu politiku,127: 307-333.

Mihalj, S, Bajt, V., Pankov, M. (2008). Reorganizacija identifikacionog obrasca: televizuelna izgradnja kolektivnog identiteta u ranoj fazi raspada Jugoslavije. U: Đerić G. (ur.) Intima javnosti. (str. 98-126). Beograd: Fabrika knjiga.

Rogač, Lj. (2011) Kulturne aktivnosti Srbije u Evropi i svetu: 2000 - 2010. Kultura: časopis za teoriju i sociologiju kulture i kulturnu politiku, br 130: 331-349.

Stojković, B. (2002). Identitet i komunikacija. Beograd: Čigoja štampa. 
Švob Đokić, N. Primorac, J., N. Obuljen (2013). Historical perspective: cultural policies and i nstruments-Croatia. Preuzeto 20. 11. 2013. sa http://www.culturalpolicies.net/web/croatia.php?aid=1.

Van Dijk, T. (2008). Discourse and context: a sociocognitive approach. Cambridge, New York: Cambridge University Press.

Van Dijk, T. (1998). Ideology: A Mutlidisciplinary Approach. London: Sage Publications.

Ugrešić, D. (2008). Kultura laži. Beograd: Fabrika knjiga.

Vukanović, M. (2011). Pogled na kulturu. Zakoni i prakse u Srbiji i pet država članica Evropske unije. Beograd: Zavod za proučavanje kulturnog razvitka.

Wiesand, A. J. (2005). ,European Cultural Co-operation“ in the G2CC-LAB-

Environment(Portal)Definition and Elements of a Conceptual Framework. Bonn: ERICArts Preuzeto 11. 10. 2015. sa http://www.labforculture.org/en/ resources-for-research/contents/research-in-focus/european-culturalcooperation/european-cultural-co-operation-in-the-g2cc-lab-environmentportal-definition-and-elements-of-a-conceptual-framework

Arhivski tekstovi u elektronskoj formi:

Izveštaj Reportera bez granica o medijskim slobodama za 2018. godinu. Preuzeto 25.4. 2018 sa https://rsf.org/en/rsf-index-2018-hatred-journalism-threatensdemocracies

Izveštaj Ministarstva kulture Hrvatske „Povrat kulturnih dobara“ Preuzeto 20.8.2018 sa https://www.min-kulture.hr/default.aspx?id=9899 

ПЕДАГОГИЈА 
